\title{
Diagnostic relevance of 18F-FDG PET/CT in newly diagnosed patients with monoclonal gammopathy of undetermined significance (MGUS): Single-center experience
}

\author{
V. SANDECKA ${ }^{1}$, Z. ADAM ${ }^{1}$, M. KREJCI', M. STORK ${ }^{1, *}$, Z. REHAK², R. KOUKALOVA ${ }^{2}$, S. SEVCIKOVA ${ }^{3}$, L. BROZOVA ${ }^{4}$, Z. KRAL $^{1}$, J. MAYER ${ }^{1}$, L. POUR ${ }^{1}$ \\ ${ }^{1}$ Department of Internal Medicine, Hematology and Oncology, University Hospital, Brno, Czech Republic; ${ }^{2}$ Department of Nuclear Medicine, \\ Masaryk Memorial Cancer Institute, Brno, Czech Republic; ${ }^{3}$ Babak Myeloma Group, Department of Pathological Physiology, Faculty of Medi- \\ cine, Masaryk University, Brno, Czech Republic; ${ }^{4}$ Institute of Biostatistics and Analyses, Faculty of Medicine, Masaryk University, Brno, Czech \\ Republic \\ ${ }^{*}$ Correspondence: stork.martin@fnbrno.cz
}

Received November 4, 2019 / Accepted February 6, 2020

\begin{abstract}
Monoclonal gammopathy of undetermined significance (MGUS) is a known precursor of more serious cancers, such as multiple myeloma (MM), Waldenström macroglobulinemia (MW) and other lymphoproliferative disorders. Using 18F-FDG PET/CT, we aimed to evaluate its benefit in early detection of various accompanying disorders and illnesses in MGUS patients. We prospectively analyzed the diagnostic relevance of 18F-FDG PET/CT in 390 newly diagnosed MGUS patients. On 18F-FDG PET/CT scans, the presence of focal or diffuse areas of detectable increased tracer uptake was recorded in 37 (9.5\%) MGUS patients. The most frequent pathology was lymphadenopathy (3.8\%), followed by thyroid diseases $(2.1 \%)$, rheumatic diseases (1.8\%), and other solid malignancies (1.5\%). These results have major implications for confirmed associations of MGUS with numerous malignant and non-malignant disorders. We believe that 18F-FDG PET/ CT imaging in newly diagnosed MGUS patients may be useful in early detection of other serious pathologies, not only in predicting progression of MGUS to active MM, and should be strongly recommended if available.
\end{abstract}

Key words: monoclonal gammopathy, cancer, multiple myeloma, PET/CT

Monoclonal gammopathy of undetermined significance (MGUS) is one of the most common pre-malignant disorders and affects approximately $3.5 \%$ of the population over 50 years of age $[1,2]$. IgG and IgA isotypes MGUS are defined by serum monoclonal immunoglobulin (M-protein) $<30 \mathrm{~g} / \mathrm{l}$ in serum, bone marrow (BM) plasma cell percentage $<10 \%$, and absence of signs or symptoms related to multiple myeloma (MM) (CRAB criteria: hypercalcemia, renal insufficiency, anemia, or bone lesions) or other lymphoproliferative disorders [3]. IgM isotype MGUS is defined by serum IgM M-protein less than $30 \mathrm{~g} / \mathrm{l}$, bone marrow lymphoplasmacytic infiltration $<10 \%$, and absence of end-organ damage. Lightchain MGUS is defined by an abnormal $\kappa / \lambda$ free light-chain (FLC) ratio, an increase in the concentration of the involved light chain, and absence of expression of a monoclonal peak of immunoglobulin heavy chain in serum on immunofixation [3]. IgG or IgA MGUS patients typically progress to MM, and IgM MGUS patients typically develop into Waldenström macroglobulinemia (MW) or other lymphoproliferative disorders [4]. Patients with a light chain only asymp- tomatic monoclonal gammopathy are at risk of developing light-chain MM or immunoglobulin light-chain amyloidosis (AL amyloidosis) $[1,5,6]$. Progression of MGUS to MM or other related malignancies occurs at a rate of approximately $1 \%$ per year [7-10]. Furthermore, MGUS patients have an approximately 2-8-fold increased risk of developing myeloid malignancies, including myelodysplastic syndrome (MDS), acute myeloid leukemia, and polycythemia vera $[11,12]$ and an approximately 1.5 -fold increased risk of developing a non-hematologic malignancy [11-13].

Among newer imaging techniques, positron emission tomography (PET) integrated with computed tomography (PET/CT) using glucose labeled with the positron-emitting radionuclide $18 \mathrm{~F}$ (fluorodeoxyglucose (18F-FDG)) is a standard technique in the diagnosis and management of serious illnesses, several types of tumors and for FDG-avid lymphomas, it is crucial for staging and treatment response [14-16]. Furthermore, it is a reliable technique for assessing early skeletal involvement and for predicting outcomes at the onset of MM [17-20]. The International Myeloma Working 
Group (IMWG) consensus aimed to provide recommendations for the optimal use of PET/CT in MM patients and other plasma cell disorders, including smoldering multiple myeloma (SMM) and solitary plasmacytoma [21]. Nevertheless, data for the role of PET/CT in diagnostic relevance in MGUS patients are still limited.

Since MGUS patients have an increased risk of developing hematologic and non-hematologic malignancies, we performed PET/CT imaging in all newly diagnosed MGUS patients. Our data show that using PET/CT imaging in newly diagnosed MGUS patients may be useful for the early detection of various malignant and non-malignant disorders, not only for verification of CRAB symptoms. According to our knowledge, this is the first recommendation for the use of PET/CT imaging in MGUS patients.

\section{Patients and methods}

Patient selection. In total, 390 consecutively diagnosed MGUS patients were enrolled in a prospective clinical imaging study. Patients presenting with underlying osteolytic lesions and/or paramedullary lesions, arising from bone, and/or extra-medullary disease, arising in soft tissues, were excluded from the study as they were considered to have active MM, according to the new diagnostic criteria [3]. At the time of PET/CT imaging, these patients showed no specific symptoms indicative of later diagnosed illnesses. All MGUS patients were diagnosed and monitored at the Department of Internal Medicine, Hematology and Oncology at the University Hospital Brno, Czech Republic, from January 2010 to December 2016. The diagnosis of MGUS was made according to the updated 2010 IMWG diagnostic criteria [22]. Written informed consent approved by the Ethics committee of the hospital was obtained from all patients before enrollment of the study in accordance with the current version of the Helsinki declaration. Imaging scans were reviewed by a radiologist and a nuclear medicine physician. The baseline characteristics of the entire patient group are listed in Table 1. The median age of all patients was 63 years (range 22-93 years), and there were equal numbers of males and females. Only 15.4\% (60/390) patients were younger than 50 . The predominant monoclonal isotype was IgG, which occurred in $69.6 \%(271 / 390)$ of patients. Overall $12.4 \%$ (48/390) of patients had an M-protein value $\geq 1.5 \mathrm{~g} / \mathrm{dl}$ at diagnosis. The abnormal value of FLC ratio ( $\mathrm{k}$ to $\lambda$ ratio $<0.26$ or $>1.65)$ was detected in $43.4 \%(169 / 390)$ of patients. Immunoparesis was detected in $25.2 \%$ (98/390) of patients.

Laboratory evaluation. All patients underwent myeloma specific tests, including serum and urine immunofixation electrophoresis, serum free light chain assay, serum immunoglobulin, serum beta-2-microglobulin, and lactate dehydrogenase. Bone marrow aspirates and biopsies were obtained for cytological and histopathological evaluation of plasma cell infiltration. Clonality assessment and aberrant plasma cell percentage was determined in bone marrow aspirate by
8 color flow cytometry using European Myeloma Network Gating criteria [23]. Immunoparesis was defined as one or more immunoglobulins less than the lower limit normal for our laboratory's respective reference range ( $\operatorname{IgA}<0.61 \mathrm{~g} / \mathrm{l}$, $\operatorname{IgG}<7.67 \mathrm{~g} / \mathrm{l}, \operatorname{IgM}<0.5 \mathrm{~g} / \mathrm{l})$. FLC estimation was carried out using serum FLC assay (FreeliteH, The Binding Site Limited, Birmingham, UK) performed on a Dade Behring Nephelometer (Deerfield, IL, USA) [24]. A complete radiological examination of the skeleton was performed in all patients to exclude osteolytic lesions.

18F-FDG PET/CT technique. Patients underwent whole body PET/CT imaging within 6 months of MGUS diagnosis, performed at the Department of Nuclear Medicine, Masaryk Memorial Cancer Institute, Brno, Czech Republic; images were thereafter uploaded in a system for central review. PET/ CT scans were acquired according to a local protocol (applying EANM (European Association of Nuclear Medicine) PET procedure guidelines for FDG studies) [25]. All patients had standard preparation prior to the examination, including restriction of physical activity for $12 \mathrm{~h}$, fasting for at least $6 \mathrm{~h}$, capillary glycemia below $10 \mathrm{mmol} / \mathrm{l}(180 \mathrm{mg} / \mathrm{dl})$ prior to $18 \mathrm{~F}-\mathrm{FDG}$ administration and peroral hydration with $500-1,000 \mathrm{ml}$ of plain water. $18 \mathrm{~F}-\mathrm{FDG}$ was administered in a dose of 3.5-4.5 MBq/kg. After an in vivo accumulation time of 55 to 90 minutes, whole body scanning including the tip of the skull to the lower third of the femoral shafts and the upper limb (total body range) were performed. PET/CT examination was performed utilizing the hybrid scanner Biograph $64 \mathrm{HR}+$ Siemens Erlangen, Germany. All images were iteratively reconstructed and corrected for attenuation. 18F-FDG uptake was assessed visually and also semi-quantitatively in the defined region of interest (ROI) with the calculation of target-to-liver ratios. Liver 18F-FDG uptake (SUVmax) was used as a reference base (measured within the ROI located in the centrum of the right liver lobe). A target-to-liver ratio $>1.0$ was considered positive in all mentioned regions.

\section{Results}

In total, 390 newly diagnosed MGUS patients were evaluated; these patients did not have any lytic lesions on skeletal survey [3]. On PET/CT scans, the presence of focal or diffuse areas of detectable increased tracer uptake on at least two consecutive slices was recorded in 9.5\% (37/390) of MGUS patients. The most frequent pathology was lymphadenopathy $3.8 \%(15 / 390)$, followed by thyroid disorders $2.1 \%(8 / 390)$, and rheumatic diseases $1.8 \%$ (7/390). Primary malignancy was confirmed by histological verification in $4.8 \%(19 / 390)$ patients. This included 3.1\% (12/390) patients with lymphoproliferative diseases and $1.8 \%(7 / 390)$ patients with solid tumors.

Lymphadenopathy was the most common pathology, detected in $3.8 \%$ of evaluable patients. All patients with detected lymphadenopathy underwent biopsy of lymph nodes. Overall, 3.1\% (12/390) of patients were reclassi- 
fied as having lymphoproliferative diseases. Patients were divided into low risk and aggressive lymphoma according to WHO classification [26]. Among the remaining 3 patients with lymph nodes abnormalities, 1 patient was diagnosed with Sjögren's syndrome, 1 patient with sarcoidosis, and 1 patient with reactive lymphadenopathy, without the detection of malignant cells after the biopsy. None of the patients had symptoms typical for lymphoproliferative diseases at the time of PET/CT imaging.

Thyroid disease was the second most common pathology in our study, observed in eight $(2.1 \%)$ patients. In one patient, thyroid carcinoma was diagnosed; the remaining seven $(1.8 \%)$ patients were diagnosed with focal thyroid abnormalities, nontoxic struma. All patients had thyroid hormones tested within the normal range at the time of PET/ CT imaging.

Rheumatologic diseases were the third most common pathology, occurring in seven $(1.8 \%)$ of all scanned patients. Specifically, there were four (1.1\%) patients diagnosed with rheumatoid arthritis, two (0.5\%) patients with polymyalgia rheumatic, and one patient with giant-cell temporal arteritis. Schwannoma of the femoral nerve was identified in one case. The description of overall imaging findings in every patient with MGUS is provided in Table 2.

\section{Discussion}

MGUS is a known precursor of more serious diseases, such as MM, MW, and primary amyloidosis, but most patients with MGUS do not develop a plasma cell malignancy [7]. However, numerous reports suggest an association of MGUS with a wide variety of other malignant and nonmalignant diseases [27-29]. Because of the high prevalence of MGUS in the general population, it is difficult to distinguish true pathogenic relationships from coincidental associations. In fact, approximately $3 \%$ of patients with any given disease will be found to have MGUS based on coincidence [30]. Furthermore, MGUS is one of the most common pre-malignant disorders, with the rate of progression to $\mathrm{MM}$ or related malignancies at approximately $1 \%$ per year [7-10].

Most experts do not routinely recommend imaging in MGUS patients with serum IgG M-protein of $15 \mathrm{~g} / \mathrm{l}$ or $<$ or IgA M-protein of $10 \mathrm{~g} / \mathrm{l}$ or $<$ without bone pain. For all other patients with apparent conventional MGUS, imaging should be considered (skeletal survey for non-IgM M-protein; CT scan of chest, abdomen, and pelvis for IgM MGUS) [31].

However, since MGUS may be connected to an increased risk of developing hematologic as well as solid malignancies or other disorders, we believe that all newly diagnosed MGUS patients should be evaluated by PET/CT imaging. We are aware that the PET/CT imaging is associated with higher radiation exposure than many other conventional diagnostic radiology examinations. On the other hand, we know that MGUS is rare in young patients (pts; age $<40$ years at diagnosis), with a prevalence of $<0.3 \%$, representing
Table 1. Patients' clinical and laboratory characteristics.

\begin{tabular}{|c|c|c|}
\hline Clinical characteristics & & Number of patients (\%) \\
\hline \multicolumn{3}{|l|}{ Sex } \\
\hline females & & $206(52.9 \%)$ \\
\hline males & & $184(47.1 \%)$ \\
\hline \multicolumn{3}{|l|}{ Age (at diagnosis) } \\
\hline younger than 50 & & $60(15.4 \%)$ \\
\hline $50-59$ & & $96(24.6 \%)$ \\
\hline $60-69$ & & $116(29.7 \%)$ \\
\hline older than 69 & & $118(30.3 \%)$ \\
\hline \multicolumn{3}{|l|}{ M-protein type } \\
\hline IgG & & $271(69.6 \%)$ \\
\hline $\operatorname{IgM}$ & & $54(13.8 \%)$ \\
\hline $\operatorname{Ig} A$ & & $48(12.2 \%)$ \\
\hline biclonal & & $13(3.2 \%)$ \\
\hline other & & $4(1.1 \%)$ \\
\hline \multicolumn{3}{|l|}{ Light chain type } \\
\hline kappa & & $225(57.7 \%)$ \\
\hline lambda & & $150(38.4 \%)$ \\
\hline biclonal & & $15(3.9 \%)$ \\
\hline \multicolumn{3}{|l|}{ Immunoparesis } \\
\hline Yes & & $98(25.2 \%)$ \\
\hline No & & $292(74.8 \%)$ \\
\hline M-protein in serum (g/dl) & $\geq 1.5$ & $48(12.4 \%)$ \\
\hline Kappa/lambda ratio & $\begin{array}{l}<0.26 \\
\text { or }>1.65\end{array}$ & $169(43.4 \%)$ \\
\hline BMPC infiltration - cytology (\%) & $>5$ & $49(12.6 \%)$ \\
\hline BMPC infiltration - histology (\%) & $>5$ & $51(13.0 \%)$ \\
\hline Albumin (g/dl) & $<3.5$ & $18(4.6 \%)$ \\
\hline Beta2 microglobulin (mg/l) & $>3$ & $76(19.5 \%)$ \\
\hline Hemoglobin (g/dl) & $<12$ & $63(16.1 \%)$ \\
\hline LDH $(\mu \mathrm{kat} / \mathrm{l})$ & $>3.75$ & $145(37.2 \%)$ \\
\hline Platelets (10E9/l) & $<150$ & $30(7.6 \%)$ \\
\hline Creatinine $(\mu \mathrm{mol} / \mathrm{l})$ & $>115$ & $49(12.6 \%)$ \\
\hline Calcium total level (mmol/l) & $>2.2$ & $340(87.1 \%)$ \\
\hline Normal PC - CD19+ (\%) & $\leq 5$ & $101(26.0 \%)$ \\
\hline Abnormal PC - CD56+ (\%) & $\geq 95$ & $19(4.8 \%)$ \\
\hline
\end{tabular}

Abbreviations: M-protein, monoclonal-protein; Ig, immunoglobulin; $\mathrm{BM}$, bone marrow; PC, plasma cells; Immunoparesis: $\operatorname{IgA}<0.61 \mathrm{~g} / \mathrm{l}$, $\operatorname{IgG}<7.67 \mathrm{~g} / \mathrm{l}, \operatorname{IgM}<0.5 \mathrm{~g} / \mathrm{l}$;

approximately $2 \%$ of all patients with MGUS [2]. Therefore, we hypothesized that the presence of monoclonal immunoglobulin in young patients may be associated with a higher risk of malignant or nonmalignant diseases [32]. Despite the higher radiation exposure, we believe that PET/CT imaging should be recommended also for young newly diagnosed MGUS patients.

On PET/CT scans, the presence of focal or diffuse areas of detectable increased tracer uptake was recorded in 37 (9.5\%) MGUS patients. The most common detected pathology was lymphadenopathy (3.8\%) followed by thyroid diseases $(2.1 \%)$, rheumatic diseases $(1.8 \%)$, and other solid tumors (1.5\%). 
The association of MGUS and well-differentiated B-cell NHL is a well-known phenomenon [33-36]. Already in 1978, Lennert et al. reported that approximately $20 \%$ of all patients with lymphoplasmacytic lymphoma have serum monoclonal immunoglobulin [37]. The results of our study showed that nearly $4 \%(15 / 390)$ of all MGUS patients had lymphadenopathy, whereas $3.1 \%(12 / 390)$ patients were reclassified as having lymphoproliferative diseases after the biopsy. Five patients had low risk lymphoma and seven patients had aggressive lymphomas, Table 2.

Systemic autoimmune diseases, especially primary Sjögren's syndrome, are one of the best examples of non-hematological diseases, which often present with monoclonal gammopathy. In the 1980s, Moutsopoulos and later in 2012, Brito-Zerón [38-40] reported the presence of monoclonal immunoglobulins in Sjögren's syndrome patients and their association with extraglandular manifestations and lymphoproliferative disorders. Subsequent studies reported that up to $20 \%$ of patients with primary Sjögren's syndrome may be associated with MGUS [41]. In contrast, our study of 390 newly diagnosed MGUS patients revealed only one patient with newly recognized Sjögren's syndrome. As for the remaining two patients with lymph nodes abnormalities detected by PET/CT imaging, sarcoidosis was detected in one patient and reactive lymphadenopathy, without the detection of malignant cells after biopsy, was detected in the other patients. The association of sarcoidosis with MGUS or MM is not well described, but few cases of patients with both sarcoidosis and MM have been reported in the literature [42].
The second most common pathology in our study was thyroid disease, observed in $2.1 \%$ (8/390) of patients. Finally, $1.8 \%(7 / 390)$ of the patients presented with non-malignant thyroid disease, mainly nontoxic struma. Although thyroid disease is not frequently associated with MGUS, some studies presented an increased rate of this pathology in MGUS patients compared to the general population [43].

Rheumatic diseases were the third most common pathology, occurring in $1.8 \%(7 / 390)$ of all scanned MGUS patients. Specifically, there were $1.1 \%(4 / 390)$ of patients with rheumatoid arthritis, $0.5 \%(2 / 390)$ patients with polymyalgia rheumatic, and 1 patient with giantcell temporal arteritis. It is known that specific rheumatic diseases have consistently been associated with MGUS. A Spanish study found rheumatic diseases to be the third associated pathology with a higher incidence of MGUS, after infections and heart diseases [44]. Significantly elevated risk of MGUS was found in patients with a history of all subcategories of autoimmune diseases and specific conditions, such as rheumatoid arthritis, systemic sclerosis, Sjögren's syndrome, pernicious anemia, immune thrombocytopenia, Guillain-Barré syndrome, celiac disease, chronic rheumatic heart disease, ankylosing spondylitis, polymyalgia rheumatica, giant cell arteritis, and aplastic anemia. A family history of autoimmune disease was associated with a significantly increased risk of MGUS, but not with MM. Both family history and personal history of autoimmune disease were independent predictors of risk of MGUS [45]. A population-based study had already shown the association of autoimmune conditions and the risk of

Table 2. Patients' types of pathologies: histological subtypes.

\begin{tabular}{|c|c|c|}
\hline Types of pathologies & Description-Subtype & Number of patients \\
\hline \multicolumn{3}{|l|}{ Lymphadenopathy $(n=15)$} \\
\hline \multirow[t]{6}{*}{ Lymphoproliferative diseases } & CLL/small lymphocytic lymphoma & 4 \\
\hline & Plasmablastic lymphoma & 3 \\
\hline & Diffuse large B-cell lymphoma & 2 \\
\hline & Hodgkin's lymphoma & 1 \\
\hline & Burkitt's lymphoma & 1 \\
\hline & MALT lymphoma & 1 \\
\hline Diseases of the musculoskeletal system and connective tissue & Sjögren's syndrome & 1 \\
\hline Inflammatory disease & Sarcoidosis & 1 \\
\hline Other & Reactive lymphadenopathy & 1 \\
\hline \multicolumn{3}{|l|}{ Thyroid disease $(n=8)$} \\
\hline Non-cancerous & Nontoxic struma & 7 \\
\hline Cancerous & Thyroid carcinoma & 1 \\
\hline \multirow[t]{3}{*}{ Rheumatologic disease $(n=7)$} & Rheumatoid arthritis & 4 \\
\hline & Polymyalgia rheumatic & 2 \\
\hline & Giant-cell temporal arteritis & 1 \\
\hline \multirow[t]{3}{*}{ Other malignancies $(n=6)$} & Colorectal cancer & 4 \\
\hline & Prostate cancer & 1 \\
\hline & Thymoma & 1 \\
\hline Other $(n=1)$ & Schwannoma of femoral nerve & 1 \\
\hline
\end{tabular}


specific lymphoid malignancies [46]. The specific mechanisms are not well understood but chronic antigen stimulation assumes an important role [47, 48].

While MGUS patients are known to be at an increased risk of developing MM, MW, and primary amyloidosis, the risk of developing non-hematologic malignancies is less clear. A recent report suggested that MGUS patients have a 1.56-fold increased risk of developing non-hematologic malignancies. In 2011, Mailankody et al. reported an increased risk for people with MGUS of developing non-melanoma skin, endocrine, breast, kidney and urinary tract, respiratory, male reproductive system, and GI cancers [11]. In our study, 1.8\% (7/390) of the newly diagnosed MGUS patients presented with solid malignancies. The most common malignancy was colorectal cancer in $1.0 \%(4 / 390)$ of the patients followed by prostate and thyroid cancer, which were present in one patient each. Thymoma was diagnosed in one patient. Our findings particularly reflected results from the Czech National Cancer Registry. Czech men are most frequently affected by prostate cancer, closely followed by colorectal and lung cancer. The most frequent diagnoses in Czech women are breast cancer, followed by colorectal, lung, and uterine cancer. Contrary to previous reports [11], we did not find other solid malignancies, such as breast or lung cancer, in our group of MGUS patients.

Our study is the first report of the PET/CT imaging in MGUS patients. In 390 evaluable MGUS patients, we documented nearly $10 \%$ of patients with malignant and nonmalignant disorders, including aggressive lymphomas and solid tumors. We want to emphasize that all MGUS patients with newly detected illnesses at the time of PET/ CT imaging were asymptomatic at the time of the scan. Because of PET/CT imaging, we were able to detect unexpected disorders in these patients - at the time when these patients showed no symptoms. Despite the fact that PET/CT imaging is an expensive diagnostic procedure and its availability is limited, we strongly recommend its usage in all newly diagnosed MGUS patients regardless of type and size of M- protein.

In conclusion, MGUS is a premalignant plasma cell disorder that may progress into multiple myeloma, Waldenström macroglobulinemia, or other lymphoproliferative disorders. Our findings clearly suggest this association. We detected nearly $10 \%$ of patients with serious illnesses - before the first symptoms - in newly diagnosed MGUS patients. Our results show that PET/CT imaging can be recommended not only for MGUS patients with suspected SMM or active MM but also for all newly diagnosed MGUS patients with aim of early detection of other disorders.

Acknowledgments: The authors would like to thank all colleagues who are involved in the care of MGUS patients, especially to doctors at the Masaryk Memorial Cancer Institute, from the Department of Nuclear Medicine for their excellent cooperation.

\section{References}

[1] DISPENZIERI A, KATZMANN JA, KYLE RA, LARSON DR, MELTON LJ et al. Prevalence and risk of progression of light-chain monoclonal gammopathy of undetermined significance: a retrospective population-based cohort study. Lancet 2010; 375: 1721-1728. https://doi.org/10.1016/ S0140-6736(10)60482-5

[2] KYLE RA, THERNEAU TM, RAJKUMAR SV, LARSON DR, PLEVAK MF et al. Prevalence of monoclonal gammopathy of undetermined significance. N Engl J Med 2006; 354: 1362-1369. https://doi.org/10.1056/NEJMoa054494

[3] RAJKUMAR SV, DIMOPOLOUS MA, PALUMBO A, BLADE J, MERLINI G et al. International Myeloma Working Group updated criteria for the diagnosis of multiple myeloma. Lancet Oncol 2014; 15: e538-458. https://doi. org/10.1016/S1470-2045(14)70442-5

[4] KYLE RA, THERNEAU TM, RAJKUMAR SV, REMSTEIN ED, OFFORD JR et al. Long-term follow-up of IgM monoclonal gammopathy of undetermined significance. Blood 2003; 102: 3759-3764. https://doi.org/10.1182/ blood-2003-03-0801

[5] WEISS BM, ABADIE J, VERMA P, HOWARD RS, KUEHL WM. A monoclonal gammopathy precedes multiple myeloma in most patients. Blood 2009; 113: 5418-5422. https:// doi.org/10.1182/blood-2008-12-195008

[6] WEISS BM, HEBREO J, CORDARO DV, ROSCHEWSKI MJ, BAKER TP et al. Increased serum free light chains precede the presentation of immunoglobulin light chain amyloidosis. J Clin Oncol 2014; 32: 2699-2704. https://doi. org/10.1200/JCO.2013.50.0892

[7] KYLE RA, THERNEAU TM, RAJKUMAR SV, OFFORD JR, LARSON DR et al. A long-term study of prognosis in monoclonal gammopathy of undetermined significance. N Engl J Med 2002; 346: 564-569. https://doi.org/10.1056/ NEJMoa01133202

[8] CESANA C, KLERSY C, BARBARANO L, NOSARI AM, CRUGNOLA $\mathrm{M}$ et al. Prognostic factors for malignant transformation in monoclonal gammopathy of undetermined significance and smoldering multiple myeloma. J Clin Oncol 2002; 20: 1625-1634. https://doi.org/10.1200/ JCO.2002.20.6.1625

[9] MONTOTO S, BLADE J, MONTSERRAT E. Monoclonal gammopathy of undetermined significance. N Engl J Med 2002; 346: 2087-2088.

[10] SANDECKA V, HAJEK R, POUR L, SPICKA I, SCUDLA $\mathrm{V}$ et.al. A first Czech analysis of 1887 cases with monoclonal gammopathy of undetermined significance. Eur J Haematol 2017; 99: 80-90. https://doi.org/10.1111/ejh.12894

[11] MAILANKODY S, PFEIFFER RM, KRISTINSSON SY, KORDE N, BJORKHOLM M et al. Risk of acute myeloid leukemia and myelodysplastic syndromes after multiple myeloma and its precursor disease (MGUS). Blood 2011; 118: 4086-4092. https://doi.org/10.1182/blood-2011-05-355743

[12] ROEKER LE, LARSON DR, KYLE RA, KUMAR S, DISPENZIERI A et al. Risk of acute leukemia and myelodysplastic syndromes in patients with monoclonal gammopathy of undetermined significance (MGUS): a population-based study of 17315 patients. Leukemia 2013; 27: 1391-1393. https://doi.org/10.1038/leu.2013.34 
[13] GREGERSEN H, MELLEMKJAER L, SALLING IJ, SORENSEN HT, OLSEN JH et al. Cancer risk in patients with monoclonal gammopathy of undetermined significance. Am J Hematol 2000; 63: 1-6. https://doi.org/10.1002/(sici)10968652(200001)63:1<1::aid-ajh1>3.0.co;2-m

[14] BARTEL TB, HAESSLER J, BROWN TLY, SHAUGHNESSY JD JR, VAN RHEE F et al. F18-fluorodeoxyglucose positron emission tomography in the context of other imaging techniques and prognostic factors in multiple myeloma. Blood 2009; 114: 2068-2076. https://doi.org/10.1182/ blood-2009-03-213280

[15] REHAK Z, VASINA J, NEMEC P, FOJTIK Z, KOUKALOVA R et al. Various forms of (18)F-FDG PET and PET/CT findings in patients with polymyalgia rheumatica. Biomed Pap Med Fac Univ Palacky Olomouc Czech Repub 2015; 159: 629-636. https://doi.org/10.5507/bp.2015.026

[16] ADAM Z, REHAK Z, KOUKALOVA R, BORTLICEK Z, KREJCI $M$ et al. PET-CT documented complete 4-year remission of Erdheim-Chester disease after treatment with Cladribine. Vnitr Lek 2015; 61: 251-259.

[17] ZAMAGNI E, PATRIARCA F, NANNI C, ZANNETTI B, ENGLARO E et al. Prognostic relevance of 18-F FDG PET/ CT in newly diagnosed multiple myeloma patients treated with up-front autologous transplantation. Blood 2011; 118: 5989-5995. https://doi.org/10.1182/blood-2011-06-361386

[18] USMANI SZ, MITCHELL A, WAHEED S, CROWLEY J, HOERING A et al. Prognostic implications of serial 18-fluoro-deoxyglucose emission tomography in multiple myeloma treated with total therapy 3 . Blood 2013; 121: 1819-1823. https://doi.org/10.1182/blood-2012-08-451690

[19] WAHEED S, MITCHELL A, USMANI S, EPSTEIN J, YACCOBY $S$ et al. Standard and novel imaging methods for multiple myeloma: correlates with prognostic laboratory variables including gene expression profiling data. Haematologica 2013; 98: 71-78. https://doi.org/10.3324/haematol.2012.066555

[20] ZAMAGNI E, CAVO M. The role of imaging techniques in the management of multiple myeloma. Br J Haematol 2012; 159: 499-513. https://doi.org/10.1111/bjh.12007

[21] CAVO M, TERPOS E, NANNI C, MOREAU P, LENTZSCH $S$ et al. Role of 18F-FDG PET/CT in the diagnosis and management of multiple myeloma and other plasma cell disorders: a consensus statement by the International Myeloma Working Group. Lancet Oncol 2017; 18: e206-e217. https:// doi.org/10.1016/S1470-2045(17)30189-4

[22] KYLE RA, DURIE BG, RAJKUMAR SV, LANDGREN O, BLADE $J$ et al. Monoclonal gammopathy of undetermined significance (MGUS) and smoldering (asymptomatic) multiple myeloma: IMWG consensus perspectives risk factors for progression and guidelines for monitoring and management. Leukemia 2010; 24: 1121-1127. https://doi.org/10.1038/ leu. 2010.60

[23] RAWSTRON AC, ORFAO A, BEKSAC M, BEZDICKOVA L, BROOIMANSET RA et al. Report of the European Myeloma Network on multiparametric flow cytometry in multiple myeloma and related disorders. Haematologica 2008; 93: 431-438. https://doi.org/10.3324/haematol.11080
[24] KATZMANN JA, CLARK RJ, ABRAHAM RS, BRYANT $S$, LYMP JF et al. Serum reference intervals and diagnostic ranges for free kappa and free lambda immunoglobulin light chains: relative sensitivity for detection of monoclonal light chains. Clin Chem 2002; 48: 1437-1444.

[25] BOELLAARD R, DELGADO-BOLTON R, OYEN WJ, GIAMMARILE F, TATSCH K et al. FDG PET/CT EANM procedure guidelines for tumour imaging: version 2.0. Eur J Nucl Med Mol Imaging 2015; 42: 328-354. https://doi. org/10.1007/s00259-014-2961-x

[26] HARRIS NL, JAFFE ES, DIEBOLD J, FLANDRIN G, MÜLLER-HERMELINK HK et al. World Health organization classification of neoplastic diseases of the hematopoietic and lymphoid tissues. Report of a Clinical Advisory Committee Meeting. J Clin Oncol 1999; 17: 3835-3849. https://doi. org/10.1200/JCO.1999.17.12.3835

[27] KISSEL JT, MENDELL JR. Neuropathies associated with monoclonal gammopathies. Neuromuscul Disord 1996; 6: 3-18. https://doi.org/10.1016/0960-8966(95)00021-6

[28] GREGERSEN H, MELLEMKJAER L, SALLING IBSEN J, SØRENSEN HT, OLSEN JH et al. Cancer risk in patients with monoclonal gammopathy of undetermined significance. Am J Hematol 2000; 63: 1-6. https://doi.org/10.1002/ (sici)1096-8652(200001)63:1<1::aid-ajh1>3.0.co;2-m

[29] DAOUD MS, LUST JA, KYLE RA, PITTELKOW MR. Monoclonal gammopathies and associated skin disorders. J Am Acad Dermatol 1999; 40: 507-535; quiz 536-538. https://doi.org/10.1016/s0190-9622(99)70434-2

[30] BIDA JP, KYLE R, THERNEAU TM, MELTON LJ, PLEVAK MF et al. Disease Associations With Monoclonal Gammopathy of Undetermined Significance: A Population-Based Study of 17,398 Patients. Mayo Clin Proc 2009; 84: 685-693. https://doi.org/10.1016/S0025-6196(11)60518-1

[31] DONK N, PALUMBO A, JOHNSEN HE, ENGELHARDT $\mathrm{M}, \mathrm{GAY} \mathrm{F}$ et al. The clinical relevance and management of monoclonal gammopathy of undetermined significance and related disorders: recommendations from the European Myeloma Network. Haematologica 2014; 99: 984-996. https:// doi.org/10.3324/haematol.2013.100552

[32] PANGL,KUMARS,LAKSHMANA,KYLERA, RAJKUMAR SV. Prognosis of young patients with monoclonal gammopathy of undetermined significance. JClin Oncol 2019;37: 80498049. https://doi.org/10.1200/JCO.2019.37.15_suppl.8049

[33] ECONOMOPOULOS T, PAPAGEORGIOU S, PAPPA V, PAPAGEORGIOU E, VALSAMI S et al. Monoclonal gammopathies in B-cell non-Hodgkin's lymphomas. Leuk Res 2003; 27: 505-508. https://doi.org/10.1016/s01452126(02)00277-1

[34] PANGALIS GA, MOUTSOPOULOS HM, PAPADOPOULOS NM, COSTELLO R, KOKKINOU K et al. Monoclonal and oligoclonal immunoglobulins in the serum of patients with B-chronic lymphocytic leukemia. Acta Haematol 1988; 80: 23-27. https://doi.org/10.1159/000205593

[35] PANGALIS GA, NATHWANI BN, RAPPAPORT H. Malignant lymphoma, well differentiated lymphocytic. Its relationship with chronic lymphocytic leukemia and macroglobulinemia of Waldenström. Cancer 1977; 39: 999-1010. https://doi.org/10.1002/1097-0142(197703)39:3<999::aidcncr2820390302>3.0.co;2-r 
[36] MAGRATH I, BENJAMIN D, PAPADOPOULOS N. Serum monoclonal immunoglobulin bands in undifferentiated lymphomas of Burkitt and non-Burkitt types. Blood 1983; 61: 726-731.

[37] LENNERT K. Malignant Lymphomas Other Than Hodgkin's disease. Histology, Cytology, Ultrastructure, Immunology. New York: Springer-Verlag, 1978; 209-251.

[38] BRITO- ZERÓN P, RETAMOZO S, GANDIA M, AKASBI $\mathrm{M}$, PÉREZ-DE-LIS $\mathrm{M}$ et al. Monoclonal gammopathy related to Sjögren syndrome: a key marker of disease prognosis and outcomes. J Autoimmun 2012; 39: 43-48. https://doi. org/10.1016/j.jaut.2012.01.010

[39] MOUTSOPOULOS HM, STEINBERG AD, FAUCI AS, LANE HC, PAPADOPOULOS NM. High incidence of free monoclonal lambda light chains in the sera of patients with Sjogren's syndrome. J Immunol 1983; 130: 2663-2665.

[40] MOUTSOPOUlOS HM, COSTELLO R, DROSOS AA, MAVRIDIS AK, PAPADOPOULOS NM. Demonstration and identification of monoclonal proteins in the urine of patients with Sjögren's syndrome. Ann Rheum Dis 1985; 44: 109-112. https://doi.org/10.1136/ard.44.2.109

[41] BRITO-ZERÓN P, RAMOS-CASALS M, NARDI N, CERVERA R, YAGÜE J et al. Circulating monoclonal immunoglobulins in Sjögren syndrome: prevalence and clinical significance in 237 patients. Medicine (Baltimore) 2005; 84: 90-97. https://doi.org/10.1097/01.md.0000157398.37679.47

[42] DACHS R, HORN A, KOORNHOF H, DE JAGER L, MAQUNGO $S$ et al. Double pathology, sarcoidosis associated with multiple myeloma: A case report. J Bone Oncol 2014; 3: 61-65. https://doi.org/10.1016/j.jbo.2014.02.002
[43] MALTEZAS D, EFTYCHIA N, PAPAIOANNOU P, BITSANI A, TZENOU T et al. Study of MGUS-Series: Disease Evolution, Coexistant Disorders and Other Clinical Observations. Blood 2015; 126: 5323. https://doi.org/10.1182/ blood.V126.23.5323.5323

[44] GONZÁLEZ GARCÍA ME, FERNANDEZ-ALVAREZ C, MARINAS R, GONZÁLEZ-HUERTA AJ, ARIAS MIRANDA MI et al. A series of 618 cases of monoclonal gammopathies of undetermined significance: predictive factors of disappearance of monoclonal component or evolution to malignant gammopathies. Rev Clin Esp 2008; 208: 288-294. https://doi.org/10.1157/13123188

[45] LINDQVIST EK, GOLDIN LR, LANDGREN O, BLIMARK C, MELLQVIST UH et al. Personal and family history of immune-related conditions increase the risk of plasma cell disorders: a population-based study. Blood 2011; 118: 62846491. https://doi.org/10.1182/blood-2011-04-347559

[46] ANDERSON LA, GADALLA S, MORTON LM, LANDGREN O, PFEIFFER R et al. Population-based study of autoimmune conditions and the risk of specific lymphoid malignancies. Int J Cancer 2009; 125: 398-405. https://doi. org/10.1002/ijc.24287

[47] RAPOSO A, PEIXOTO D, BOGAS. Monoclonal gammopathy and rheumatic diseases. Acta Reumatol Port 2014; 39: $12-18$.

[48] JORGENSEN C, GUERIN B, FERRAZZI V, BOLOGNA C, SANY J. Arthritis associated with monoclonal gammapathy: clinical characteristics. Br J Rheumatol 1996; 35: 241-243. https://doi.org/10.1093/rheumatology/35.3.241 